\section{THERMOdYNAMic Study OF POlymer EleCtrolyte MEMBRANe PREPARATION bY NON-SOLVENT INDUCED Phase Separation}

\author{
Endah R Dyartantia,b, Agus Purwantob, I Nyoman Widiasa ${ }^{a}$, Heru \\ Susantoa*
}

aDepartment of Chemical Engineering, Diponegoro University, Semarang, Indonesia

bDepartment of Chemical Engineering, Universitas Sebelas Maret, Surakarta, Indonesia
Article history

Received

3 October 2017

Received in revised form

28 December 2017

Accepted

1 March 2018

Published online

16 May 2018

${ }^{*}$ Corresponding author heru.susanto@undip.ac.id

\section{Graphical abstract}

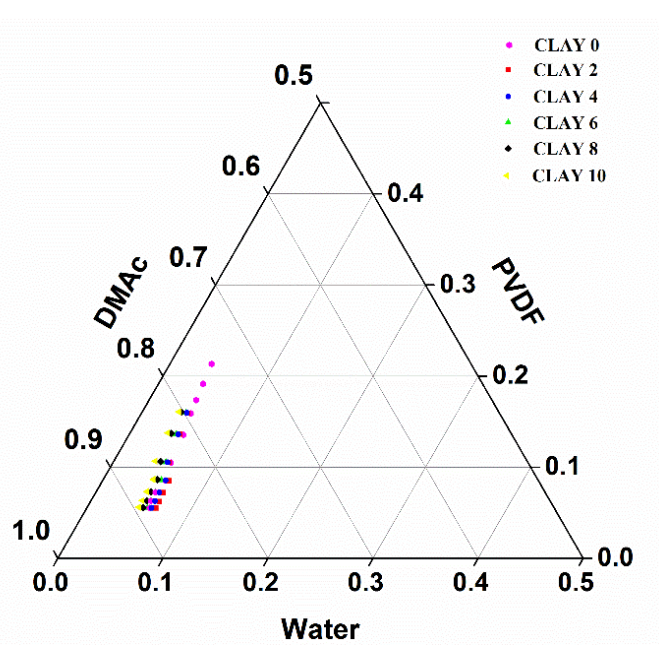

\begin{abstract}
The composition of both the polymer solution and the non-solvent determines the resulted membrane morphology during membrane preparation through non-solvent induced phase separation (NIPS) method. In the porous polymer electrolyte membranes (PEMS), a specified porosity and uniform pore membranes are required; therefore prediction of membrane morphology is essential. The Dimensional parameter of thermodynamic was determined to find the diffusional rate between DMAc solvent and Water nonsolvent during the membranes preparation. The influences of the addition of nano-clay as filler and polyvinylpyrrolidone (PVP) addition as pore-forming agent on the thermodynamic parameter were investigated. The resulted nanocomposites were characterized by measuring their porosity and electrolyte uptake as well as by a scanning electron microscopy. The composition of non-solvent required to induce phase separation of the casting solution was determined by cloud point experiment. By adding the content of additives the binodal line shifts to polymer/solvent axis, moreover MG reduces and DSBC raises and the thermodynamic parameter increased. It was obtained that the solubility parameters $\left(\Delta_{\mathrm{i}_{\mathrm{j}}}\right)$ between solvent-additive are $\Delta$ DMAc/nano-clay $=0.787\left(\mathrm{MPa}^{0.5}\right), \Delta \mathrm{PVP} / \mathrm{DMAC}=$ $5.536\left(\mathrm{MPa}^{0.5}\right)$, and The Interaction parameters $(\chi)$ are $\chi \mathrm{DMAc} /$ nano-clay $=1.661$ $\left(\mathrm{MPa}^{0.5}\right), \chi_{\mathrm{DMAC} / \mathrm{PVP}}=1.449\left(\mathrm{MPa}^{0.5}\right)$.
\end{abstract}

Keywords: NIPS, PVDF, Thermodynamic parameter, PVP, nano-clay

(C) 2018 Penerbit UTM Press. All rights reserved

\subsection{INTRODUCTION}

The Polymer Electrolyte (PE) membranes is a important part of a lithium-ion battery performance. It separates anode and cathode and supports the movement of ions over the electrolyte that entraps in its pores $[1,2]$.
One of the most critical characteristics of PE membrane is pore structure, which includes pore size and porosity. Therefore, tailoring the structure of the porous polymer membranes is very important. Several studies have been done to modify the Polymer Electrolyte Membrane (PEMs) structure. These studies 
can be categorized into two groups, i.e., (i) modification of the PEMs structure to improve the size and distribution of pores [2-6], and (ii) method to develop electrochemical performing of the PEMs [7, 8].

Membranes are usually prepared via non-solvent Induced Phase Separation (NIPS) because this method provides the construction of formation membrane structures in a handled and can be duplicated [9, 10]. The basic concept of this technique is a membranes solution is casting on a support medium or passed through a specially formed medium (spinneret) and then soaked in a non-solvent. Phase inversion processes and membrane formation may occur due to non-solvent induction into the polymer solution either by solid-liquid (s-I) or liquidliquid (I-I) demixing, conditional on the kind of host matrix and the precipitation settings [9]. This phase brings the membranes into a thermodynamically unstable state. In the immersion process of the polymer solution, the solvent also diffuses into a nonsolvent. Then polymer-rich phase will solidify after the separation process phases occur in a while for forming membrane pores. It means the properties of the polymer solution and coagulation bath could generously influence the structure and performance of membranes.

The introduction of an appropriate additive to polymer solution is usually performed. The additives used in several studies included inorganic salts, low molecular weight organics, water, polymers, fillers, surfactants, or the combination of them [11, 12] Certainly, these additives influence the structure and properties of the resulting membranes.

Poly(ethylene glycol) (PEG) and poly(vinyl pyrrolidone) (PVP) are extensively used as additives in membrane structure modification [11, 13, 14]. Lang and co-workers reported that addition of PVP to polymer solution influenced the morphologies, crystallization precipitation kinetics, performances, and permeation of PVDF membranes [14]. Han and Nam [[2]] also studied the influence of PVP on the rheological and thermodynamic characteristic in PSF membrane preparation. Chenggui et al., studied kinetic pertinent and thermodynamic of PVDF membranes prepared by phase separation using NMP and deionized water as solvent and non-solvent respectively [15].

Recently, many detailed studies have reported the use of polymer electrolyte membranes for lithium-ion battery performance improvement [15-17]. Several scientists have investigated the effects of PVP additives on PVDF film performance $[4,6,18,19]$.

In this research, a ternary phase diagram was illustrated experimentally for PVDF / nano-clay / DMAC / Water system. The impact of additives (PVP and nano-clay) on the structure of PEMs was explored by calculating the thermodynamic parameter of the nanocomposites. For different concentrations of additives, thermodynamic parameters determined, and the relations between the morphology and thermodynamic parameters of membranes were explored. Then the membranes were identified by porosity and electrochemical performance of the batteries.

A phase separation process of casting solution was explored with a phase diagram. A ternary diagram is depicted in Figure 1. The importance of an additive in the polymer casting is increased the volume fraction of polymer and increased synergy between the solvent and functional groups. In the introduces of an additive, the binodal line shifted to the polymersolvent line, and the single-phase area reduces [14]. Therefore, the solidifying stage is quickened and the precipitation channel will be accelerated. The products in the configuration of more porous films [5].

The thermodynamic parameter of the polymer solution can be determined in the relationship between The Degree of Shift in binodal curve (DSBC) and Miscibility Gap(MG). The DSBC determines the thermodynamical changes of the polymer solution. For an additive encouraged thermodynamic change, DSBC is computed by the following equation [6]:

$D S B C=\frac{M G_{w o / \text { additive }}-M G_{w / \text { additive }}}{M G_{w / \text { additive }}}$

The Miscibility Gap (MG), as appeared in Figure 1, is the separation between polymer/solvent axis and binodal line. It depends on the measure of the added substance affecting the phase inversion process of a casting solution. As shown in Figure 1, The Miscibility gap (MG) is the gap between The polymer-solvent axis and binodal line. A dimensionless parameter is described in equation 2 to computation the impact of the thermodynamic parameter of polymer solution on the structure of the membranes:

$$
T=D S B C \times X_{\text {solvent/additive }}
$$

The Interaction between additive and solvent ( $X$ solvent/additive ) is determined by the following equation.

$$
X_{\text {solvent/additive }}=\frac{v_{1}}{R T} \Delta_{\text {solvent/additive }}
$$

where $R$ is the ideal gas constant, $\delta$ is the solubility parameters and $\mathrm{v}$ represents the molar volume of the solvent, and. $\Delta_{\mathrm{i} / \mathrm{j}}\left(\Delta_{\text {solvent/additive }}\right)$ is computed by equation (4).

$$
\begin{aligned}
\Delta_{i / j}= & \left(\delta_{p / i}-\delta_{p / j}\right)^{2}+\left(\delta_{h / i}-\delta_{h / j}\right)^{2}+ \\
& \left(\delta_{d / i}-\delta_{d / j}\right)^{2}
\end{aligned}
$$

In this equation, $\delta$ is the solubility parameter and $\delta \mathrm{h}, \delta \mathrm{p}$, $\delta$ d represented the hydrogen bond, polar interaction and the dispersive interaction, respectively. Lower $\Delta_{\mathrm{i} / \mathrm{j}}$ promotes more significant affinity between two ingredients. 


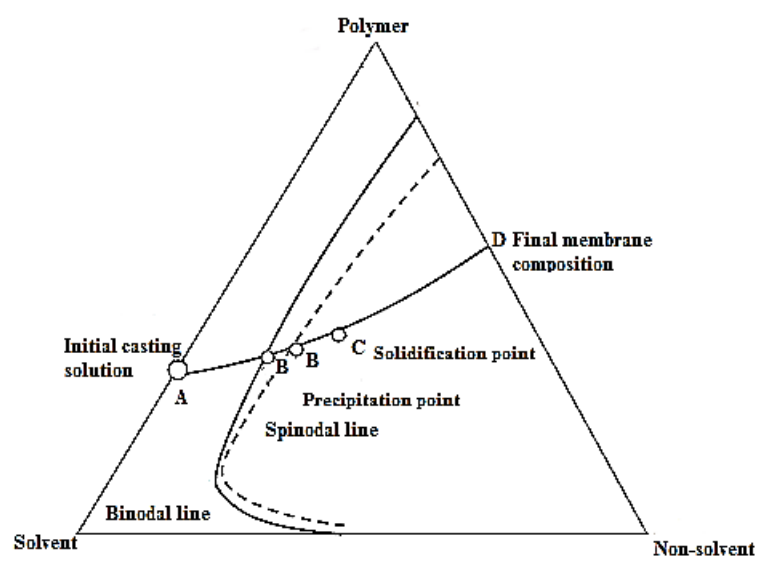

Figure 1 Ternary phase diagram

\subsection{METHODOLOGY}

\subsection{Materials}

The primary material used was polymer Polyvinylidene fluoride (PVDF, MW 600,000, MTI Co.), polyvinylpyrrolidone (PVP) (Merck, MW 25,000 g/mol), $\mathrm{N}, \mathrm{N}$-dimethylacetamide (DMAc, Merck) and octadecyl amine-modified montmorillonite nano-clay (MMT, Sigma-Aldrich). The nonsolvent used was deionized water.

The electrolyte solution is, $1 \mathrm{M}$ lithium hexafluorophosphate $\left(\mathrm{LiPF}_{6}\right)$ in ethylene carbonate (EC) / dimethyl carbonate (DMC) / Diethyl carbonate (DEC) (MTI Co.). $\mathrm{LiFePO}_{4}$ cathode and Graphite Anode

\subsection{The Turbidimetric Titration}

The cloud points of casting solutions determined by the turbidimetric titration method at $25^{\circ} \mathrm{C}$. This data represents the equilibrium phase separation of the polymer precipitation from a polymer solution. The PVDF was dissolved in solvent DMAC at a certain concentration. When PVP used as a chemical addition, The PVDF was initially dissolved in DMAC and then added to the PVP.

\subsection{Membrane Preparation}

Membranes with various concentration of Nano-clay and PVP (Table 1) were made by NIPS technique. First, nano-clay particles were dispersed in a DMAc solvent using ultrasonic sonicator at a temperature of $35^{\circ} \mathrm{C}$. After that, The PVDFhost matrix polymer was dissolved under continuous stirring for three hours at $45^{\circ} \mathrm{C}$. Then, PVP was added to the solution and stirred for at least two hours until a homogeneous mixture was achieved. The solution mixture was let stand without stirring until all bubbles had disappeared. The solution mixture was cast on glass support with a thickness of $150 \mu \mathrm{m}$ with an automatic film coater (MSK-AFA-II, MTI corp.). The membranes were directly immersed in water at $25^{\circ} \mathrm{C}$ for $72 \mathrm{~h}$. Before drying in a vacuum oven, the formed membranes were dried under air at room temperature for $24 \mathrm{~h}$. Table 1 shows the various membrane compositions prepared in this study.

\subsection{Membrane Characterization}

Membrane porosity (P) was measured via the $n$ butanol absorption method. In this process, the dry membrane was first weighed and then dipped immersed in a solution of n-butanol for 2 hours. After that, the wet membrane was weighed, and the mass of the n-butanol absorption was calculated. The membrane porosity (P) was calculated using the following equation.

$$
P(\%)=\frac{M_{\mathrm{BuOH}} / \rho_{\mathrm{BUOH}}}{\mathrm{M}_{\mathrm{BuOH}} / \rho_{\mathrm{BUOH}}+M_{\mathrm{p}} / \rho_{\mathrm{P}}}
$$

where $M_{p}$ is the mass of dry membrane and $\mathrm{M}_{\mathrm{BuOH}}$ is the mass of membrane-absorbing butanol, $\rho p$ is the membrane density, and $\rho \mathrm{BuOH}$ is the density of the membrane following the absorption of butanol [21].

\subsection{Ionic Conductivity and Battery Performance}

Ionic conductivity was performed by soaking a membrane into a liquid electrolyte. The samples sandwiched between ss blocking electrodes in CR2032 coin cell cases. The impedance measurements were carried out using a HIOKI LCR HiTester Model 3532 for frequencies ranging from $42 \mathrm{~Hz}$ to $5 \mathrm{MHz}$ at an amplitude of $10 \mathrm{mV}$. Moreover, the ionic conductivity was determined by the equation (6).

$$
\sigma=\frac{d}{R_{b} S}
$$

where $\sigma$ is the ionic conductivity, $d$ is the thickness of the sample, $S$ is the area of the specimen, and $R_{b}$ is the bulk resistance, respectively.

For investigated the performance of as prepared membranes in a battery, The gel electrolyte was sandwiched between a graphite anode and a lithium iron phosphate (LiFePO4)cathode in the battery coin cells (CR2032). The battery were assembled in a glove box filled with argon. The cells were placed in an automatic charge/discharge Battery Analyzer (0.02 $10 \mathrm{~mA}$, MTI corp.), and tested between 2.5 and $3.65 \mathrm{~V}$ under room temperature at a C-rate of 0.2 .

\subsection{RESULTS AND DISCUSSION}

\subsection{Investigation of The Binodal Line}

The binodal line for the various content of additive pore-forming agent (PVP) and Filler (Nano clay) was 
calculated by the turbiditic metric titration method. The results are depicted in Figure 2, by increasing the Nano clay and PVP loading the binodal line shifts to the polymer/solvent line. Hence, fewer nonsolvent (water) is required for precipitation of polymer mixture and the trend for demixing raised. Therefore the addition of Filler (nano-clay) or pore forming agent (PVP) enhanced the thermodynamic instability.

\subsection{The Thermodynamic Parameter}

Table 1 shown The Hanson solubility parameters for determining the thermodynamic parameter. In this study, the composite will be more established. $\delta d, \delta p$, and $\delta h$ for PVP and nano-clay were determined by the Hoftyzer and Van Krevelen technique [20]. Based on Table 1 and Eqs. (3) and (4), $\triangle \mathrm{DMAc/ \text {nano-clay } =}$ $0.787\left(\mathrm{MPa}^{0.5}\right), \quad \triangle \mathrm{PVP} / \mathrm{DMAC}=5.536\left(\mathrm{MPa}^{0.5}\right)$, and $\chi \mathrm{DMAc} /$ nano-clay $=1.661\left(\mathrm{MPa}^{0.5}\right), \quad \chi \mathrm{DMAc} / \mathrm{PVP}=1.449$ $\left(\mathrm{MPa}^{0.5}\right) . \Delta_{\mathrm{i} / \mathrm{j}}$ is the solubility of substances $\mathrm{i} \& \mathrm{j}$. The greater $\Delta_{\mathrm{i} / \mathrm{j}}$ causes lower affinity between substances. The MG, DSBC and thermodynamic parameters were calculated from research results in Figure 2, Equation (1) and (2) respectively. The results are shown in Table 2.

Table 1 Hanson solubility parameter.

\begin{tabular}{lrrr}
\hline \multicolumn{1}{c}{ Components } & $\boldsymbol{\delta}_{\mathrm{p}}(\mathbf{M P a})^{1 / 2}$ & $\delta_{\mathrm{h}}(\mathbf{M P a})^{1 / 2}$ & $\delta_{\mathrm{d}}(\mathbf{M P a})^{1 / 2}$ \\
\hline PVDFa & 12.5 & 9.2 & 17.2 \\
Nano - clayb & 11.6 & 10.4 & 15.6 \\
DMACa & 11.5 & 10.2 & 16.8 \\
Watera & 16 & 42.3 & 15.6 \\
PVP25 kDac & 0.79 & 15.8 & 8.68 \\
\hline a [17]. & & & \\
b [18] & & & \\
c [19]. & & & \\
& &
\end{tabular}

By adding the fillers and pore forming agent content in the polymer solution the binodal line shifts to the polymer-solvent line are shown in Figure 2. moreover, MG reduces, and DSBC rises, hence the thermodynamic parameter rises. Higher thermodynamic parameter encourages more instability and membranes with greater porosity, uptake of the electrolyte.

At the same content of additives, the binodal line is nearer to the polymer/solvent line for PVP. So, MG is lesser. This could be correlated to the reduced number of $\Delta \mathrm{i} / \mathrm{j}$ for PVP/DMAC than for nanoclay/DMAc. It indicates that the pore-forming agent (PVP) has much affinities to dimethylacetamide than nano-clay. Mohsenpour et al. [5] measured PVP/DMAc interaction parameter of $5.49\left(\mathrm{Mpa}^{0.5}\right)$ by PVP (MW 10.000).

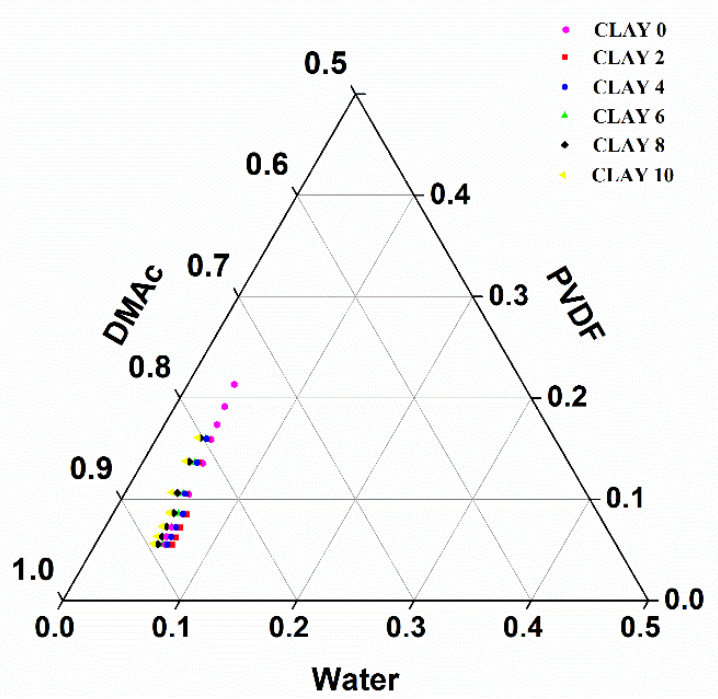

(a)

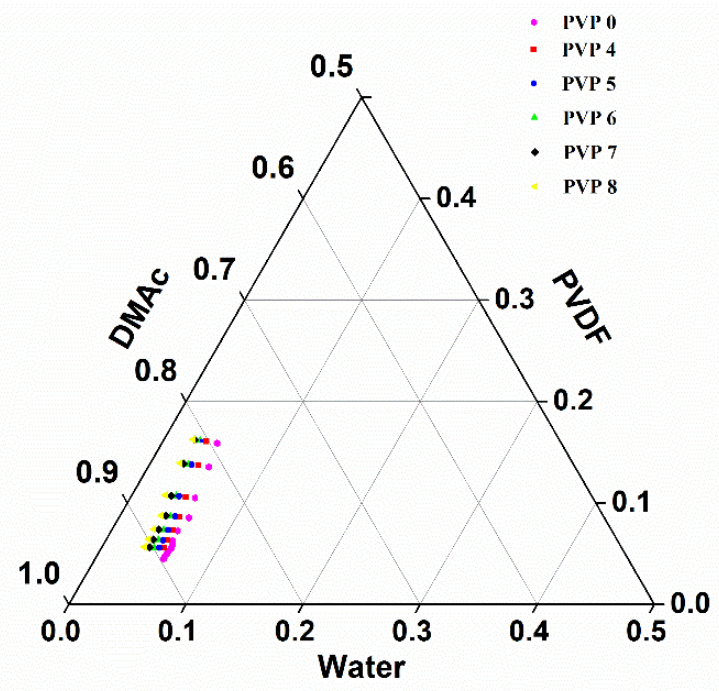

(b)

Figure 2 Phase diagram of PVDF system with a) Nano clay as additive b) PVP as an additive

Moreover, as shown in Table 2, the Miscibility Gap (MG) and The Degree of Shift in Binodal Curve (DSBC) rises hence the thermodynamic parameter rises. 
Table 2 The Thermodynamic properties of casting solution ( $\Delta \delta$ and $x$ values) determined by using Hansen solubility parameters method

\begin{tabular}{|c|c|c|c|c|c|c|c|}
\hline NO & $\begin{array}{l}\text { Synthesized } \\
\text { Membrane }\end{array}$ & $\begin{array}{l}\text { PVDF } \\
\text { (wt\%) }\end{array}$ & $\begin{array}{c}\text { PVP } \\
\text { (weight\%) }\end{array}$ & $\begin{array}{c}\text { Nano-clay } \\
\text { (wt\%) }\end{array}$ & MG & DSBC (\%) & $T$ \\
\hline 1 & $P-0$ & 10 & & & 10.601 & 0.000 & \\
\hline 2 & $C-2$ & 10 & & 2 & 7.965 & 9.107 & 15.123 \\
\hline 3 & $C-4$ & 10 & & 4 & 7.464 & 12.084 & 20.068 \\
\hline 4 & $c-6$ & 10 & & 6 & 7.018 & 18.039 & 29.956 \\
\hline 5 & $C-8$ & 10 & & 8 & 6.684 & 29.947 & 49.733 \\
\hline 6 & $C-10$ & 10 & & 10 & 6.201 & 36.252 & 60.203 \\
\hline 7 & $P-4$ & 10 & 4 & & 9.469 & 26.445 & 38.315 \\
\hline 8 & $P-5$ & 10 & 5 & & 8.745 & 33.275 & 48.211 \\
\hline 9 & $P-6$ & 10 & 6 & & 7.817 & 40.280 & 58.361 \\
\hline 10 & $P-7$ & 10 & 7 & & 7.260 & 50.788 & 73.586 \\
\hline 11 & $P-8$ & 10 & 8 & & 6.888 & 54.291 & 78.660 \\
\hline
\end{tabular}

\subsection{Membranes Characterization}

\subsubsection{SEM Images}

Scanning Electron Microscope (SEM) figures of the composites film are depicted in Figure 3. By adding $8 \%$ (weight \% of PVDF) nano clay to the casting solution, the porosity risen, but further raise the content of nano-

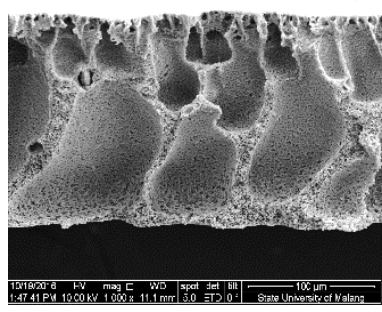

$5 \%$ PVP

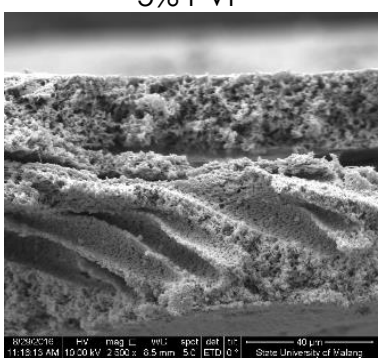

$2 \%$ nano-clay

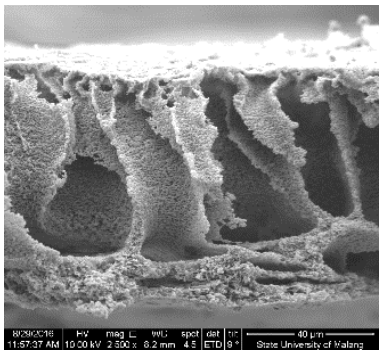

$6 \%$ PVP

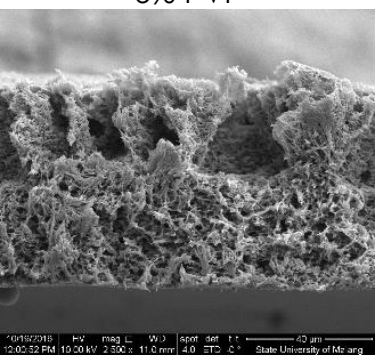

$4 \%$ nano-clay clay caused the porosity decreased. We obtained that the pore of membranes lowered by adding nano clay content. Whenever PVP was used as an additive in an add up to 7\%, porosity raised, but the porosity reduced a bit for a higher concentration of PVP. By expanding the content of PVP, the morphology of the membrane changed.

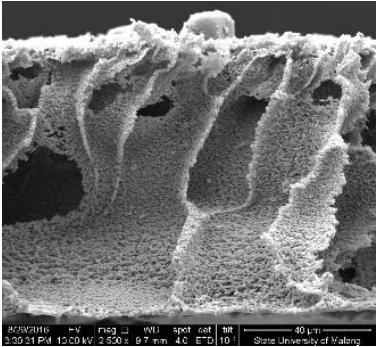

$7 \%$ PVP

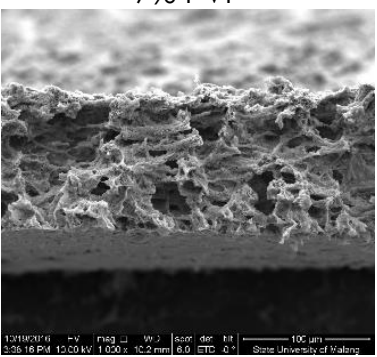

$6 \%$ nano-clay

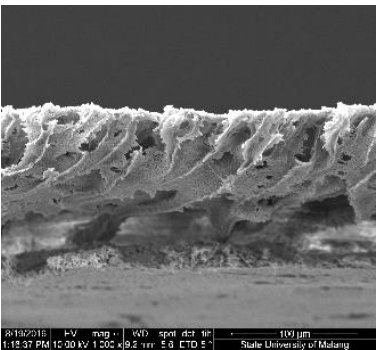

8\% PVP

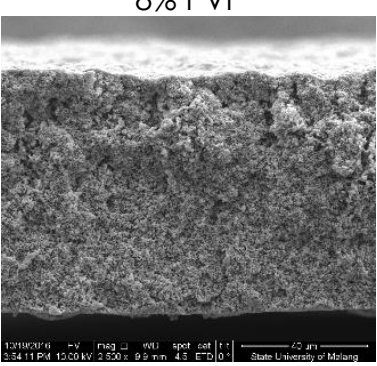

$8 \%$ nano-clay

Figure 3 SEM images of different polymer electrolyte PVDF with different concentration of nanoclay filler and PVP pore forming agent 


\subsubsection{Porosity and lonic Conductivity}

The PEMs were immersed in a solution of n-butanol, and equation (1) was applied to determine the porosity of the PEMs. Figure 4 shows the effect of nanoclay content (4a) and PVP (4b) content on the porosity and ionic conductivity of PEMs. The highest porosity of PEMs, $87 \%$, was obtained via the addition of 8 wt\% nano-clay and 7 wt\% PVP. This porosity was higher than that of PEM composed of PVDF $(75 \%)$, as reported by Deka and Kumar [10], and is comparable to PEM made of PVDF with the addition of PVP and graphene (88\%), as reported by Liu [13]. These results confirmed the performance of the addition of PVP. One of the critical characteristics of PEM for LIB separator applications is ionic conductivity. In this work, the effect of nano-clay and PVP on the conductivity of lithium-ion was investigated. The ionic conductivity was determined by sandwiching SS/Polymer electrolytes/SS (stainless steel (SS) blocking electrodes) cells at room temperature. The results in Figure $4(\mathrm{a})$ and $4(\mathrm{~b})$ shows that the maximum ionic conductivity, about $5.79 \mathrm{mS} \mathrm{cm}^{-1}$, was achieved by the PVDF PEM membrane prepared with the addition of $8 \mathrm{w}+\%$ nano-clay and $7 \mathrm{w} \%$ PVP. Excessive addition of nano-clay in the polymer electrolyte promoted aggregation that decreased the volume of the interface layer. An increase in the ionic conductivity of PEMs with fillers and pore-forming agents addition reported in earlier studies [5].

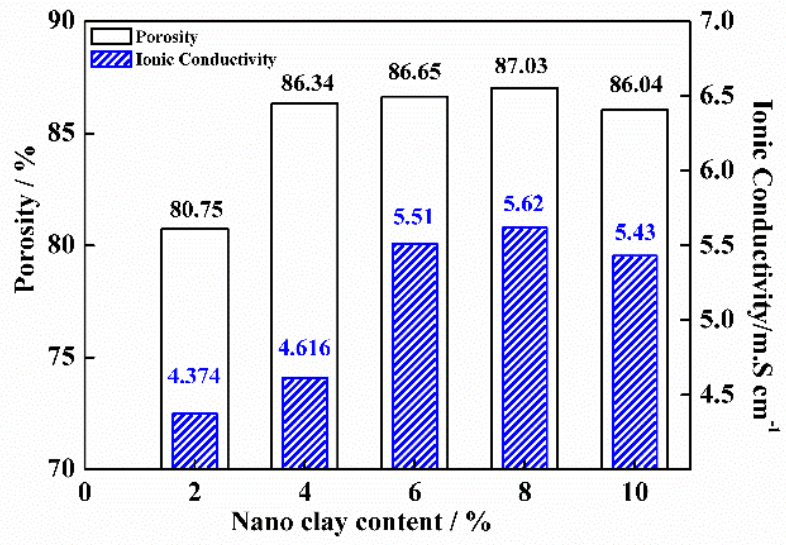

(a)

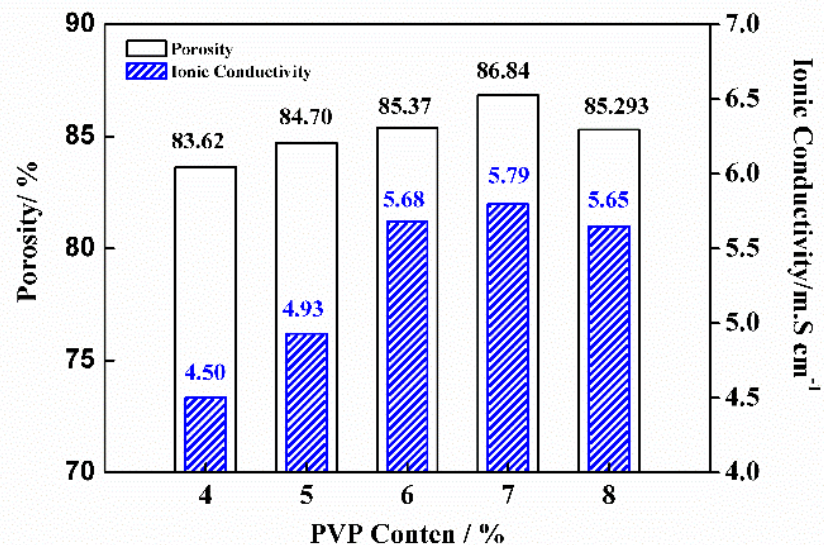

(b)

Figure 4 lonic Conductivity of PVDF membranes with different contents of (a) clay at 7 w $1 \%$ PVP and (b) PVP at 8 w $1 \%$ nano-clay

The introduce nano-clay into the PVDF with PVP as a pore-forming agent in those studies, however, has shown ionic conductivity that is higher than that of the PEMs with $\mathrm{SiO}_{2}$ - urea and graphene - PVP. Li et al. [1 1] reported PEMs with ionic conductivity of $3.652 \mathrm{mS} \mathrm{cm}$ I at $25^{\circ} \mathrm{C}$ using urea as a pore-forming agent and $10 \%$ $\mathrm{SiO}_{2}$ as a filler. Liu et al. [8] reported an ionic conductivity of $3.61 \mathrm{mS} \mathrm{cm}^{-1}$ for PVDF/graphene using PVP (20 \%wt) as a pore-forming agent and graphene with a weight of $0.002 \%$. The Higher porosity PEMs can store a higher volume of electrolytes and provides more pathways for ion migration. The conductivity of the PVDF/graphene electrolyte ions is also due to the placement of nano-clay on the internal surface of the pore channel. The nano-clay can create a lithium ion conduction pathway through Lewis acid-base interactions or around them [12]. Furthermore, the oxygen-containing functional groups in nano-clay would increase the migration of lithium ions.

\subsubsection{Battery Rate Performance}

The cycling performance of battery cells was analyzed using $\mathrm{LiFePO}_{4}$ as a cathode, graphite as an anode and a membrane prepared at a 0.2 C-rate $\left(0.42 \mathrm{~mA} \mathrm{~cm}^{-2}\right)$, with voltage cutoffs of $3.65 \mathrm{~V}$ for the upper limits and $2.2 \mathrm{~V}$ for the lower limits of ambient temperature. Figures $5(\mathrm{a})$ and (b) show discharge capacity as functions of the cycle number for the $48^{\text {th }}$ cycles of a Graphite/PEMs/LiFePO 4 cell. The effect of nano-clay on discharge capacity explained in Figure 5 (a). The cell with membrane C-4 presented the discharge capacity of 110.0 at initial and $99.9 \mathrm{~mA} \mathrm{~h} \mathrm{~g}$ 1 at $48^{\text {th }}$ cycle. The fade in capacity/cycle of the battery is $0.21 \mathrm{~mA} \mathrm{~h} \mathrm{~g}^{-1}$. However, the battery with C6 membranes showed the initial discharge capacities is 113.6 and $103.54 \mathrm{~mA} \mathrm{~h} \mathrm{~g}^{-1}$ for the final discharge capacities. Instead, the cell with $\mathrm{C}-8$ and C-10 exhibited initial discharge capacities of 123.59 and $124.43 \mathrm{~mA} \mathrm{~h} \mathrm{~g}^{-1}$ and final 114.00 and $109.00 \mathrm{~mA} \mathrm{~h} \mathrm{g-1.}$ The cell fade in capacity per cycle for $\mathrm{C}-6, \mathrm{C}-8$, and C-10 membranes have been found to be $0.209,0.199$ and $0.321 \mathrm{~mA} \mathrm{~h} \mathrm{~g}^{-1}$ respectively. Enhanced cyclability and lowest fade in capacity viewed for the membranes made with clay concentration 8 \%wt.

A similar trend observed in Figure $5(\mathrm{~b})$, for the membranes, prepared P-4, P-5, P-6, P-7, and P-8 also. Better lifecycle and lowest fade in capacity have 
been noted for the membranes made with PVP concentration 7 \%wt.

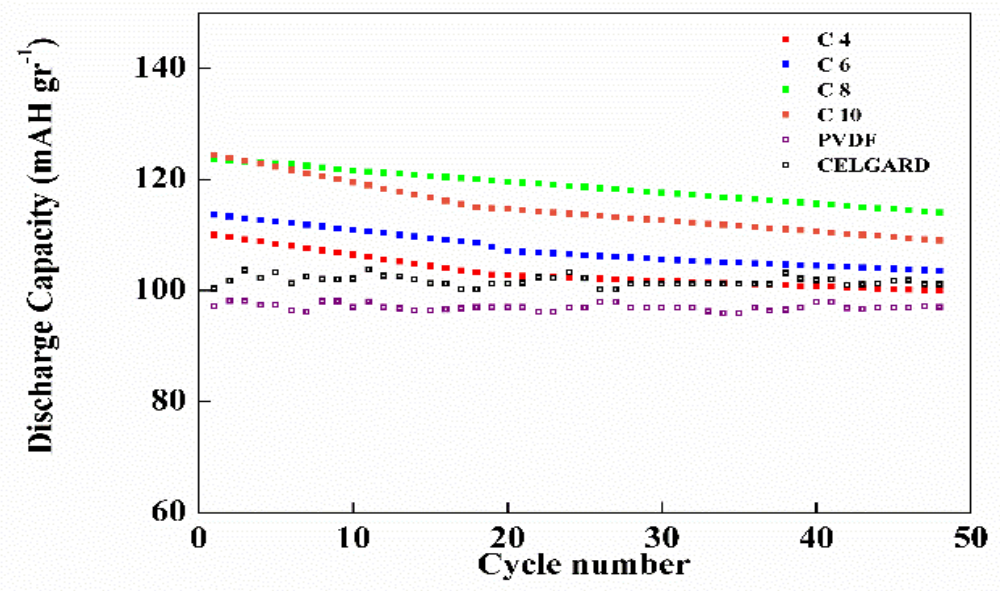

(a)

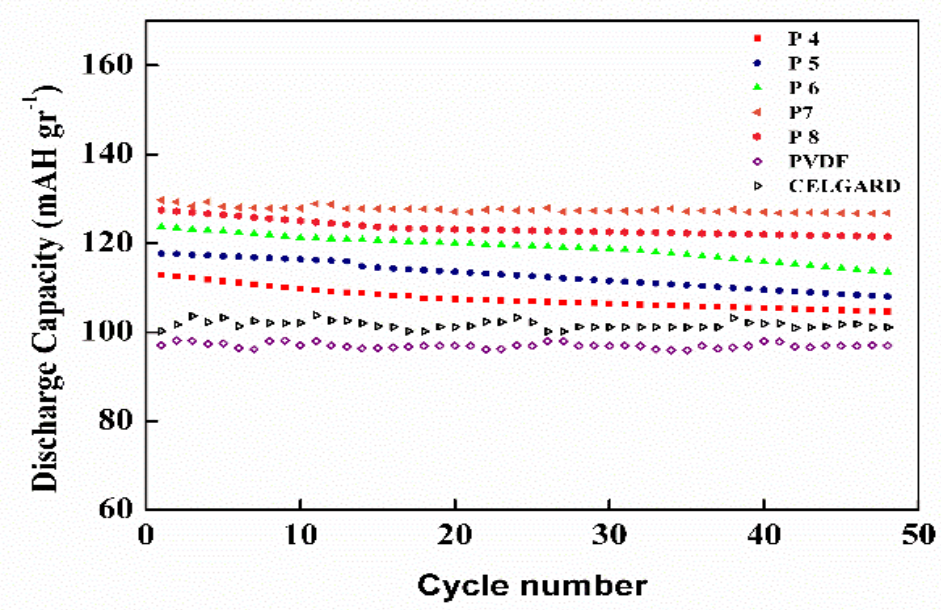

(b)

Figure 5 Discharge capacity for the Graphite /PEM/ LiFePO4 cells at a C rate of $0.2(0.4 \mathrm{~mA} \mathrm{~cm}-2)$ for different (a) nano-clay content $(4,6,8$ and $10 \% \mathrm{wt})$ and (b) PVP content $(4,5,6,7$ and $8 \% \mathrm{wt})$

\subsection{CONCLUSIONS}

A Nanocomposite Membrane-based on (PVDF) modified with a pore-forming agent (PVP), and filler (nano-clay) was well fabricated and characterized in this research. It was found the clear effect of both PVP and nano-clay, i.e., they could enhance the characteristic of membranes and battery performance (porosity, electrolyte uptake, ionic conductivity and battery charge-discharge). The fabricated cell assembled with GPEs also had excellent discharge capacity. Therefore, we believe that the modified membranes could be an achieved candidate for polymer electrolyte of the LIBS.

\section{Acknowledgment}

The authors would like to grateful to Universitas Sebelas Maret for supporting this research by Hibah PDD 2017 Grant number 1075/UN27.21/PP/2017 and The doctoral scholarship program. The authors also acknowledge to The Center for Science and Technology Advanced Materials, BATAN Indonesia for help and support with this experiment. 


\section{References}

[1] Sadrzadeh, M., Bhattacharjee, S. 2013 Rational Design of Phase Inversion Membranes by Tailoring Thermodynamics and Kinetics of Casting Solution Using Polymer Additives. J. Memb. Sci. 441: 31-44.

DOI: 10.1016/j.memsci.2013.04.009.

[2] Han, M.-J., Nam, S.-T. 2002, Thermodynamic and Rheological Variation in Polysulfone Solution by PVP and Its Effect in the Preparation of Phase Inversion Membrane. J. Memb. Sci. 202(1): 55-61. DOI: doi.org/10.1016/\$0376-7388(01)00718-9.

[3] Costa, C. M., Rodrigues, L. C., Sencadas, V., Silva, M. M. Rocha, J. G., Lanceros-Méndez, S. 2012 Effect of Degree of Porosity on the Properties of Poly (Vinylidene FluorideTrifluorethylene) for Li-lon Battery Separators. J. Memb. Sci. 407: 193-201

DOI: https://doi.org/10.1016/j.memsci.2012.03.044.

[4] Jeong, H. S., Kim, D. W., Jeong, Y. U., Lee, S. Y. 2010 Effect of Phase Inversion on Microporous Structure Development of Al2O3/poly(vinylidene Fluoride-hexafluoropropylene)based Ceramic Composite Separators for lithium-ion Batteries. J. Power Sources. 195(18): 6116-6121.

DOI: 10.1016/j.jpowsour.2009.10.085.

[5] Mohsenpour, S., Safekordi, A., Tavakolmoghadam, M. Rekabdar, F., Hemmati, M. 2016 Comparison of the Membrane Morphology based on the Phase Diagram using PVP as an Organic Additive and TiO 2 as an Inorganic Additive. Polymer (Guildf). 97: 559-568.

DOI: 10.1016/j.polymer.2016.05.069.

[6] Saljoughi, E., Mohammadi, T. 2009 Cellulose Acetate (CA)/polyvinylpyrrolidone (PVP) Blend Asymmetric Membranes: Preparation, Morphology and Performance. Desalination. $249(2): 850-854$

DOI: 10.1016/j.desal.2008.12.066.

[7] Xiao, W., Li, X., Wang, Z., Guo, H., Li, Y., Yang, B. 2012. Performance of PVDF-HFP-based Gel Polymer Electrolytes with Different Pore Forming Agents. Iran. Polym. J. 21 (11): 755-761.

DOI: $10.1007 / \mathrm{s} 13726-012-0081-7$.

[8] Liu, J., Wu, X., He, J., Li, J., Lai, Y. 2017 Preparation and Performance of a Novel Gel Polymer Electrolyte based on Poly(vinylidene fluoride)/graphene Separator for Lithium Ion Battery. Electrochim. Acta. 235: 500-507.

DOI: 10.1016/j.electacta.2017.02.042.

[9] Guillen, G. R., Pan, Y., Li, M., Hoek, E. M. V. 2011 Preparation and Characterization of Membranes Formed by Nonsolvent Induced Phase Separation: A Review. Ind. Eng. Chem. Res. 50(7): 3798-3817. DOI: $10.1021 /$ ie101928r.

[10] Li, N. N., Fane, A. G., Ho, W. S. W., Matsuura, T. 2008 Advanced Membrane Technology and Applications. Li, N. N., Fane, A. G., Ho, W. S. W., Matsuura, T., Eds. John Wiley \& Sons, Inc.: Hoboken, NJ, USA. DOI: $10.1002 / 9780470276280$.

[11] Liu, F., Hashim, N. A., Liu, Y., Abed, M. R. M., Li, K. 2011 Progress in the Production and Modification of PVDF Membranes. J. Memb. Sci. 375(1-2): 1-27. DOI: 10.1016/j.memsci.03.014

[12] Munari, S., Bottino, A., Capannelli, G., Moretti, P., Petit Bon, P. 1988. Preparation and Characterization of PolysulfonePolyvinylpyrrolidone based Membranes. Desalination. 70(13): $265-275$. DOI: 10.1016/0011-9164(88)85059-8.

[13] Kim, J.-H., Lee, K.-H. 1998. Effect of PEG Additive on Membrane Formation by Phase Inversion. J. Memb. Sci. 138(2): 153-163.
DOI: $10.1002 / 9780470276280$.

[14] Lang, W., Guo, Y., Chu, L. 2011 Evolution of the Precipitation Kinetics, Morphologies, Permeation Performances, and Crystallization Behaviors of Polyvinylidene Fluoride (PVDF) Hollow Fiber Membrane by Adding Different Molecular Weight Polyvinylpyrrolidone (PVP). Polym. Adv. Technol. 22(12): 1720-1730.

DOI: 10.1002/pat.1662

[15] Sun, A. C., Kosar, W., Zhang, Y., Feng, X. 2013 A Study of Thermodynamics and Kinetics Pertinent to Formation of PVDF Membranes by Phase Inversion. Desalination. 309: 156-164.

DOI: 10.1016/j.desal.2012.10.005

[16] Prasanth, R., Shubha, N., Hng, H. H., Srinivasan, M. 2013 Effect of Nano-clay on Ionic Conductivity and Electrochemical Properties of Poly(vinylidene fluoride) based Nanocomposite Porous Polymer Membranes and Their Application as Polymer Electrolyte in Lithium Ion Batteries. Eur. Polym. J. 49 (2): 307-318. DOI: 10.1016/j.eurpolymj.2012.10.033.

[17] Deka, M., Kumar, A. 2011 Electrical and Electrochemical Studies of Poly(vinylidene fluoride)-clay Nanocomposite Gel Polymer Electrolytes for Li-ion Batteries. J. Power Sources. 196(3): 1358-1364. DOI: 10.1016/j.jpowsour.2010.09.035

[18] Wang, M., Zhao, F., Guo, Z., Dong, S. 2004, Poly(vinylidene Fluoride-hexafluoropropylene)/organo-montmorillonite Clays Nanocomposite Lithium Polymer Electrolytes. Electrochim. Acta. 49(21): 3595-3602. DOI: 10.1016/j.electacta.2004.03.028.

[19] Chang, X., Wang, Z., Quan, S., XU, Y., Jiang, Z., Shao, L. 2014 Exploring the Synergetic Effects of Graphene Oxide (GO) and Polyvinylpyrrodione (PVP) on Poly(vinylylidenefluoride) (PVDF) Ultrafiltration Membrane Performance. Appl. Surf. Sci. 316(1): 537-548.

DOI: 10.1016/j.apsusc.2014.07.202.

[20] Guo, Y. W., Cui, W. W., Xu, W. H., Jiang, Y., Liu, H. H., Xu, J. Y., Gao, Z. Q., Liu, L. Z. 2014, Effect of PVP Hydrophilic Additive on the Morphology and Properties of PVDF Porous Membranes. Adv. Mater. Res. 981: 891-894. DOI: 10.4028/www.scientific.net/AMR.981.891.

[21] Raghavan, P., Zhao, X., Kim, J.-K., Manuel, J., Chauhan, G. S., Ahn, J.-H., Nah, C. 2008. Ionic Conductivity and Electrochemical Properties of Nanocomposite Polymer Electrolytes Based on Electrospun Poly(vinylidene fluorideco-hexafluoropropylene) with Nano-sized Ceramic Fillers. Electrochim. Acta. 54(2): 228-234.

DOI: 10.1016/j.electacta.2008.08.007.

[22] Van Krevelen, D. W., Te Nijenhuis, K. 2009. Properties of Polymers: Their Correlation with Chemical Structure; Their Numerical Estimation and Prediction from Additive Group Contributions. Elsevier.

DOI: 10.1016/0160-9327(92)90023-i.

[23] Hansen, C. M. 2007/ Hansen Solubility Parameters: A User's Handbook. CRC Press. DOI: $10.1201 / 9781420006834$.

[24] Li, Y., Xiao, W., Li, X., Miao, C., Guo, H., Wang, Z. 2014, Study on Performance of a Novel P(VDF-HFP)/SiO2 Composite Polymer Electrolyte Using Urea as Pore-forming Agent. lonics (Kiel). 20(9): 1217-1224. DOI: 10.1007/s11581-014-1081-8.

[25] Susanto, H., Ulbricht, M. 2009 Characteristics, Performance and Stability of Polyethersulfone Ultrafiltration Membranes Prepared by Phase Separation Method Using Different Macromolecular Additives. J. Memb. Sci. 327(1-2): 125-135. DOI: 10.1016/j.memsci.2008.11.025. 